\title{
Blood pressure control and adverse outcomes of COVID-19 infection in patients with concomitant hypertension in Wuhan, China
}

\author{
Jinjun Ran ${ }^{1,2} \cdot$ Ying Song ${ }^{3,4} \cdot$ Zian Zhuang $^{5} \cdot{\text { Lefei } \mathrm{Han}^{6} \cdot \text { Shi Zhao }}^{7} \cdot$ Peihua Cao ${ }^{8}$ Yan Geng ${ }^{9,10} \cdot$ Lin Xu $^{11} \cdot$ Jing Qin $^{6}$. \\ Daihai $\mathrm{He}^{5} \cdot$ Fengfu $\mathrm{Wu}^{3,4} \cdot$ Lin Yang ${ }^{6}$
}

Received: 20 July 2020 / Revised: 27 July 2020 / Accepted: 29 July 2020 / Published online: 27 August 2020

(C) The Japanese Society of Hypertension 2020

\begin{abstract}
Hypertension is a common comorbidity in hospitalized patients with COVID-19 infection. This study aimed to estimate the risks of adverse events associated with in-hospital blood pressure (BP) control and the effects of angiotensin II receptor blocker (ARB) prescription in COVID-19 patients with concomitant hypertension. In this retrospective cohort study, the anonymized medical records of COVID-19 patients were retrieved from an acute field hospital in Wuhan, China. Clinical data, drug prescriptions, and laboratory investigations were collected for individual patients with diagnosed hypertension on admission. Cox proportional hazards models were used to estimate the risks of adverse outcomes associated with BP control during the hospital stay. Of 803 hypertensive patients, 67 (8.3\%) were admitted to the ICU, $30(3.7 \%)$ had respiratory failure, $26(3.2 \%)$ had heart failure, and $35(4.8 \%)$ died. After adjustment for confounders, the significant predictors of heart failure were average systolic blood pressure (SBP) (hazard ratio (HR) per $10 \mathrm{mmHg} 1.89,95 \%$ confidence interval (CI): $1.15,3.13$ ) and pulse pressure (HR per $10 \mathrm{mmHg} 2.71,95 \% \mathrm{CI}: 1.39,5.29)$. The standard deviations of SBP and diastolic BP were independently associated with mortality and ICU admission. The risk estimates of poor BP control were comparable between patients receiving $\mathrm{ARBs}$ and those not receiving $\mathrm{ARBs}$, with the only exception of a high risk of heart failure in the nonARB group. Poor BP control was independently associated with higher risks of adverse outcomes of COVID-19. ARB drugs did not increase the risks of adverse events in hypertensive patients.
\end{abstract}

Keywords COVID-19 $\cdot$ Hypertension $\cdot$ Heart failure $\cdot$ Intensive care unit $\cdot$ Mortality

These authors contributed equally: Jinjun Ran, Ying Song, Zian Zhuang, Lefei Han, Shi Zhao, Peihua Cao

Supplementary information The online version of this article (https:// doi.org/10.1038/s41440-020-00541-w) contains supplementary material, which is available to authorized users.

Fengfu Wu

24632513@qq.com

$\triangle$ Lin Yang

1.yang@polyu.edu.hk

1 School of Public Health, Li Ka Shing Faculty of Medicine, University of Hong Kong, Hong Kong, China

2 School of Public Health, Shanghai Jiao Tong University School of Medicine, Shanghai, China

3 Department of Medical Affairs, Huoshenshan Hospital, Wuhan, China

4 No. 923 Hospital of Joint Service Supporting Force, Nanning, China

5 Department of Applied Mathematics, Hong Kong Polytechnic University, Hong Kong, China

\section{Introduction}

Early investigations on the clinical characteristics of patients with COVID-19 infection have found that

6 School of Nursing, Hong Kong Polytechnic University, Hong Kong, China

7 JC School of Public Health and Primary Care, Chinese University of Hong Kong, Hong Kong, China

8 Clinical Research Center, Zhujiang Hospital, Southern Medical University, Guangzhou, China

9 Department of Infectious Diseases, Huoshenshan Hospital, Wuhan, China

10 Department of Gastroenterology, No. 923 Hospital of Joint Service Supporting Force, Nanning, China

11 School of Public Health, Sun Yat-sen University, Guangzhou, Guangdong, China 
comorbidities significantly increase the risk of severe clinical outcomes, such as mortality, ICU admission, and mechanical ventilation [1-5]. One of the most common comorbidities among COVID-19 patients is hypertension, with a prevalence ranging from 16.9 to $31.2 \%$ in hospitalized patients in China $[3,5,6]$. Hypertension was also the most common comorbidity in ICU patients in Lombardy, Italy (49\%) and hospitalized COVID-19 patients in New York, USA $(56.6 \%)$ [7, 8]. The mechanism of exacerbation associated with underlying conditions remains unclear, and experts worldwide have called for in-depth analysis of blood pressure (BP) control in hypertension patients during the clinical course of COVID-19 [9].

The mechanisms of exacerbation of underlying cardiovascular conditions after COVID-19 infection remain unclear. One of the most cited hypotheses is the overexpression of angiotensin converting enzyme II (ACE2) in arterial endothelial and smooth muscle cells. A recent experimental study demonstrated elevated levels of ACE2 in the cardiomyocytes of patients with heart diseases [10]. Similar to SARS-CoV, the causal pathogen of COVID-19, SARS-CoV-2 virus, also targets ACE2 receptors as entry points to human host cells $[11,12]$. ACE2 and ACE2 receptors play important roles in the renin-angiotensin-aldosterone system (RAAS), and RAAS inhibitors have been widely used as antihypertension drugs. Two of these RAAS inhibitors, angiotensin II receptor blockers (ARBs) and ACE inhibitors (ACEIs), have caused great concern due to their direct interactions with ACE2 and ACE2 receptors [13]. ARBs/ACEIs have been widely recommended as antihypertensive drugs in patients with both hypertension and diabetes mellitus (DM). Notably, DM was the second most common comorbidity found in hospitalized patients with COVID-19 [3]. As a result, concerns have been raised that ARB and ACEI drugs could result in the overexpression of ACE2, facilitating virus entry and increasing susceptibility to and the clinical severity of COVID-19 infection [14]. However, theoretically, ACE2 could also degrade angiotensin II to protect the host from severe lung injury based on animal experiments of SARS-CoV [15]. To date, evidence is rather limited to support the harmful effects of ARB and ACEI drugs on COVID-19 patients with hypertension.

In addition to average levels of systolic and dialytic BP, blood pressure variability (BPV) has also been positively associated with high risks of morbidity and mortality in patients with hypertension. Recent studies also suggested that high BPV could predict a high risk of organ damage, cardiovascular events, and all-cause and cardiovascular mortality independent of mean BP in patients with hypertension or cerebrovascular disease [16, 17]. Overall, there is an urgent need to evaluate the optimal control of BP and the effect of ARB and ACEI drugs in hypertensive patients with COVID-19 infection.

\section{Material and methods}

\section{Data sources}

In this retrospective cohort study, the anonymized individual medical records from February 4 (admission of the first patient) to March 31, 2020 were retrieved from the electronic database of Huoshenshan Hospital, an acute field hospital built in Wuhan in response to the COVID-19 outbreak [18].

\section{COVID-19 infection diagnosis and classification}

The diagnosis and classification of COVID-19 infection followed the guidelines of the National Health Commission of China [19]. Patients were confirmed to have COVID-19 infection if their reverse transcription polymerase chain reaction tests of throat or nasal swabs were positive for SARS-CoV-2 virus or if both IgM and IgG were positive in serum SARS-CoV-2 antibody tests. The tests were conducted using standard kits produced by Sansure Biotech Inc. (Hunan, China). COVID-19 patients were divided into four types according to their symptoms and chest CT imaging based on the national guidelines: (1) mild cases, with mild respiratory symptoms but no signs of pneumonia in chest X-ray or CT imaging; (2) moderate cases, with respiratory symptoms and signs of pneumonia in chest Xray or CT imaging; (3) severe cases, with one of the following symptoms: respiratory rate $\geq 30 / \mathrm{min}, \mathrm{SpO}_{2} \leq 93 \%$, or $\mathrm{PaO}_{2} / \mathrm{FiO}_{2} \leq 300 \mathrm{mmHg}$; and (4) critical cases, with one of the following symptoms: respiratory failure requiring mechanical ventilation; shock; or ICU admission for other organ failures.

\section{Hypertension definition and blood pressure measurements}

Hypertension status was defined according to the selfreported medical history of each patient. Their BP was also measured by nurses using a mercury BP monitor, usually twice per day (in mornings and afternoons) after admission. The target of hypertension control during hospitalization was systolic blood pressure (SBP)/diastolic blood pressure (DBP) $<140 / 90 \mathrm{mmHg}$, according to the $2018 \mathrm{ESC} / \mathrm{ESH}$ guideline and the 2020 ISH guideline [20, 21]. Patients were classified as having poor BP control if either the average in-hospital SBP was $\geq 140 \mathrm{mmHg}$ or the average inhospital DBP was $\geq 90 \mathrm{mmHg}$. Patients were classified as having good BP control if both the average in-hospital SBP was $<140 \mathrm{mmHg}$ and the average in-hospital DBP was $<90$ mmHg. BPV was calculated as the standard deviation (SD) of the daily mean SBP/DBP during hospitalization [16]. Mean arterial pressure (MAP) and pulse pressure (PP) were 
derived from the average SBP and DBP using standard formulas.

\section{Outcomes and confounding factors}

We retrieved the incidence and dates of disease outcomes of individual patients from the medical records. The selected adverse outcomes included mortality, ICU admission, respiratory failure, and heart failure. The confounding factors were also retrieved, including age; sex; disease severity status; smoking (current smoker vs. ever/never/unknown); alcohol consumption (current drinker vs. ever/never/unknown); and comorbidities such as cancer, diabetes, coronary heart disease, cerebrovascular disease, chronic obstructive pulmonary diseases (COPD), chronic liver disease, and chronic kidney disease. Respiratory failure was defined as arterial partial pressure of oxygen $<60 \mathrm{mmHg}$ and/or arterial partial pressure of carbon dioxide $>50 \mathrm{mmHg}$ during rest. The diagnosis of heart failure followed the 2016 ESC guidelines for the diagnosis and treatment of acute and chronic heart failure [22]. The diagnosis of heart failure could be made if patients fulfilled one of the following conditions: (1) having typical symptoms (shortness of breath, edema, and fatigue) and reduced left ventricular ejection fraction $(\mathrm{LVEF}<40 \%)$; (2) exhibiting a LVEF $>40 \%$ but having symptoms and elevated natriuretic peptide and showing abnormal heart structures and/ or diastolic dysfunction in ultrasound.

\section{Statistical analysis}

Descriptive statistics were calculated for patients with poor and good control of SBP and DBP. Between-group differences were compared by Student's $t$ test, Mann-Whitney $U$ test, or ANOVA for continuous variables and by chi-square test or Fisher's exact test for categorical variables. Survival analysis was conducted by fitting univariate Cox proportional hazards (PHs) models to estimate the associations of adverse outcomes with the mean and SD of SBP and the mean and SD of DBP, MAP, and PP during hospitalization. Multivariate models were built by including all the confounding factors as covariates, together with SBP and DBP on admission. We depicted dose-response relationships of outcomes with the six BP variables by natural spline regression with two degrees of freedom that yielded the minimal Akaike information criterion in model selection. The linearity assumption was checked by the chi-square test between linear and spline regression models. We also stratified patients into two subgroups by ARB prescriptions (ever vs. never at the time of hospitalization) to estimate the effect modification of ARBs on the associations of outcomes with each BP variable in the univariate model. Then, we utilized the $z$-test to check the statistical significance of differences between these subgroups.
Several sensitivity analyses were conducted by (1) replacing the Cox PH model with the logistic regression model; (2) replacing continuous BP variables with categorical BP variables: good vs. poor SBP, good vs. poor DBP, as well as binary variables of SBP/DBP variability, MAP, and PP (overall median as a cutoff point); (3) replacing the $\mathrm{SD}$ of SBP/DBP by the coefficient of variation (CV), an alternative measurement of BPV; and (4) excluding patients who entered the ICU or died with at least one record of hypotension ( $\mathrm{SBP}<90 \mathrm{mmHg}$ and $\mathrm{DBP}<60 \mathrm{mmHg}$ ). We calculated crude and adjusted hazard ratios (HRs) and their 95\% confidence intervals (CIs) associated with each $10 \mathrm{mmHg}$ increase in average SBP, average DBP, MAP, and PP and each SD increase in SBP or DBP to estimate the effects of risk factors $(H R>1)$ and beneficial factors $(\mathrm{HR}<1)$. All analyses were carried out with $\mathrm{R}$ software (version 3.6.1) using the "survival" package.

\section{Results}

\section{Descriptive statistics of patients}

A flow chart of the data screening procedure is shown in Fig. 1. A total of 3023 patients were admitted to Huoshenshan Hospital from February 4 to March 23, 2020 and were followed up until March 31, 2020. After excluding 2135 patients without concomitant hypertension, 10 suspected COVID-19 cases, 72 cases without multiple BP measurements during hospitalization (less than three times), and 3 cases without BP measurement on admission, a total of 803 patients were included in the analysis. Of 803 hypertensive patients, $67(8.3 \%)$ were admitted to the ICU, $30(3.7 \%)$ had

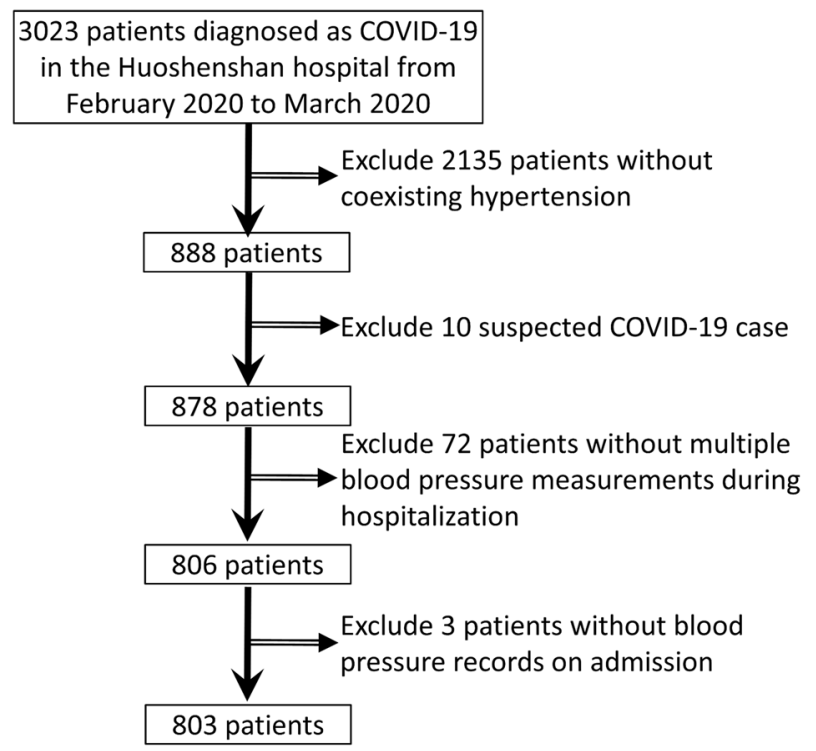

Fig. 1 Flow chart of patients included in the analysis 
Table 1 Demographic characteristics, presenting symptoms on admission and coexisting comorbidities in patients with good or poor BP control during hospitalization

\begin{tabular}{|c|c|c|c|c|}
\hline & $\begin{array}{l}\text { All } \\
(n=803)\end{array}$ & $\begin{array}{l}\text { Good BP control } \\
(n=662)\end{array}$ & $\begin{array}{l}\text { Poor BP control } \\
(n=141)\end{array}$ & $p$ \\
\hline \multicolumn{5}{|l|}{ Blood pressure, $\mathrm{mmHg}$} \\
\hline SBP on admission & $137.0 \pm 19.7$ & $134.0 \pm 18.0$ & $153.0 \pm 18.5$ & $<0.001$ \\
\hline DBP on admission & $84.2 \pm 12.8$ & $82.7 \pm 12.2$ & $91.2 \pm 13.0$ & $<0.001$ \\
\hline Average DBP & $9.5 \pm 4.2$ & $9.2 \pm 3.9$ & $11.0 \pm 5.0$ & $<0.001$ \\
\hline SD of DBP & $6.5 \pm 2.6$ & $6.3 \pm 2.5$ & $7.0 \pm 3.0$ & 0.017 \\
\hline MAP & $95.7 \pm 7.0$ & $93.6 \pm 5.3$ & $105.0 \pm 5.8$ & $<0.001$ \\
\hline Pulse pressure & $51.6 \pm 8.3$ & $49.9 \pm 6.8$ & $59.8 \pm 9.8$ & $<0.001$ \\
\hline COVID-19 severity status & & & & 0.055 \\
\hline Mild & $6(0.8 \%)$ & $3(0.5 \%)$ & $3(2.1 \%)$ & \\
\hline Moderate & $468(58.3 \%)$ & $394(59.5 \%)$ & $74(52.5 \%)$ & \\
\hline Severe & $282(35.1 \%)$ & $224(33.8 \%)$ & $58(41.1 \%)$ & \\
\hline Critical & $47(5.9 \%)$ & $41(6.2 \%)$ & $6(4.3 \%)$ & \\
\hline Age & & & & 0.592 \\
\hline$<65$ years & $338(42.1 \%)$ & $282(42.6 \%)$ & $56(39.7 \%)$ & \\
\hline$\geq 65$ years & $465(57.9 \%)$ & $380(57.4 \%)$ & $85(60.3 \%)$ & \\
\hline Sex & & & & 0.423 \\
\hline Female & $394(49.1 \%)$ & $320(48.3 \%)$ & $74(52.5 \%)$ & \\
\hline Male & $409(50.9 \%)$ & $342(51.7 \%)$ & $67(47.5 \%)$ & \\
\hline Body temperature, ${ }^{\circ} \mathrm{C}$ & $36.5 \pm 0.4$ & $36.5 \pm 0.4$ & $36.6 \pm 0.4$ & 0.345 \\
\hline Respiratory rate $>24$ breaths per min & $21(3.5 \%)$ & $19(3.9 \%)$ & $2(1.8 \%)$ & 0.396 \\
\hline Current smoker & $58(9.2 \%)$ & $53(10.3 \%)$ & $5(4.4 \%)$ & 0.068 \\
\hline Current drinker & $37(5.9 \%)$ & $34(6.6 \%)$ & $3(2.6 \%)$ & 0.151 \\
\hline \multicolumn{5}{|l|}{ Clinical symptoms } \\
\hline Fever & $402(50.1 \%)$ & $339(51.2 \%)$ & $63(44.7 \%)$ & 0.189 \\
\hline Cough & $372(46.3 \%)$ & $314(47.4 \%)$ & $58(41.1 \%)$ & 0.205 \\
\hline Dyspnea & $225(28.0 \%)$ & $195(29.5 \%)$ & $30(21.3 \%)$ & 0.063 \\
\hline Fatigue & $256(31.9 \%)$ & $216(32.6 \%)$ & $40(28.4 \%)$ & 0.376 \\
\hline \multicolumn{5}{|l|}{ Coexisting comorbidities } \\
\hline Cancer & $26(3.2 \%)$ & $20(3.0 \%)$ & $6(4.3 \%)$ & 0.434 \\
\hline Diabetes & $229(28.5 \%)$ & $188(28.4 \%)$ & $41(29.1 \%)$ & 0.953 \\
\hline Coronary heart disease & $118(14.7 \%)$ & $100(15.1 \%)$ & $18(12.8 \%)$ & 0.561 \\
\hline Cerebrovascular disease & $74(9.2 \%)$ & $60(9.1 \%)$ & $14(9.9 \%)$ & 0.871 \\
\hline COPD & $33(4.1 \%)$ & $32(4.8 \%)$ & $1(0.7 \%)$ & 0.045 \\
\hline Chronic liver disease & $23(2.9 \%)$ & $18(2.7 \%)$ & $5(3.6 \%)$ & 0.579 \\
\hline Chronic kidney disease & $10(1.3 \%)$ & $4(0.6 \%)$ & $6(4.3 \%)$ & 0.003 \\
\hline
\end{tabular}

$S B P$ systolic blood pressure, $D B P$ diastolic blood pressure, $M A P$ mean arterial pressure, $S D$ standard deviation, $C O P D$ chronic obstructive pulmonary disease respiratory failure, $26(3.2 \%)$ had heart failure, and 35 (4.8\%) died. The average follow-up time was $~ 39$ days.

Of 803 patients in our study, 609 had BP measurements on admission, and 295 (48.4\%) had normal BP on admission $(\mathrm{SBP} / \mathrm{DBP}<140 / 90 \mathrm{mmHg}$ ). The mean SBP and DBP on admission were $137.0 \mathrm{mmHg}( \pm 19.7)$ and $84.2 \mathrm{mmHg}$ $( \pm 12.8)$, respectively (Table 1$)$. A total of $82.4 \%(662 / 803)$ of COVID-19 patients had good BP control, and $17.6 \%$ (141/803) had poor BP control during hospitalization (Table 1). Compared to those with good BP control, the patients with poor BP control had higher average SBP and DBP, higher SDs of SBP and DBP, and higher MAP and PP during the period. The patients with poor $\mathrm{BP}$ control were more likely to have COPD and chronic kidney disease.

\section{Laboratory profile, clinical courses, and disease outcomes}

Laboratory investigations on admission were similar between patients with good and poor BP control, except that 
patients with the latter had higher albumin and lower total bilirubin. Patients with poor BP control were less likely to have alanine aminotransferase $>40 \mathrm{U} / \mathrm{L}$ and more likely to have creatinine $>133 \mu \mathrm{mol} / \mathrm{L}$ on admission (Table 2). Treatment during hospitalization was generally comparable between the patient groups (good vs. poor BP control). During hospitalization, there were 581, 199, 100, and 33 patients who received calcium antagonists, beta-blockers, ARBs, and thiazide diuretics, respectively (Table 2). Patients with poor BP control were more likely to be prescribed calcium antagonists, ARBs, or three types of antihypertensive drugs combined during their hospital stay.

\section{Hazard ratio (HR) of adverse outcomes}

The correlation coefficients between BP variables and outcomes were low to moderate (Supplementary Tables 1-3). Crude and adjusted HRs estimated from univariate and multivariate Cox PH models are shown in Table 3. In the univariate models, average SBP was positively associated with heart failure, whereas average DBP and MAP were negatively associated with mortality, ICU admission, and respiratory failure. Higher SBP/DBP variability and PP were associated with higher hazards of all critical events. After adjustment for confounding factors (SBP and DBP on admission, age, sex, smoking, alcohol consumption, and comorbidities), the remaining significant predictors for heart failure were average SBP (HR per $10 \mathrm{mmHg}: 1.89,95 \% \mathrm{CI}$ : 1.15-3.13) and PP (HR per $10 \mathrm{mmHg}: 2.71,95 \% \mathrm{CI}$ : 1.39-5.29), and an increase in SBP variability was also marginally associated with an increased hazard of heart failure (HR per $1 \mathrm{mmHg}$ : 1.09 , 95\% CI: 0.99, 1.20 ). Increased SBP or DBP variability was significantly associated with higher risks of mortality and ICU admission, respectively $(p<0.05)$. These BP variables had high discriminability in regard to their association with the critical events, as indicated by the area under the receiver operating characteristic curve (AUC) $>0.8$ in all multivariate models (Supplementary Table 4).

Dose-response curves show a clear trend of higher mortality hazards associated with the increasing SDs of SBP/DBP and MAP, and a similar pattern was found for the hazards of heart failure associated with average SBP, MAP, and PP (Fig. 2). A linear relationship was observed between the hazard of ICU admission and increased SDs of SBP/ DBP. The chi-square tests showed that the assumption of a linear relationship with the outcomes remained for most BP variables (Supplementary Table 5). Sensitivity analyses yielded similar effect estimates, suggesting the robustness of the main results (Supplementary Tables 6-8). The results were also consistent after excluding eight patients who died or were admitted to the ICU with at least one record of hypotension (Supplementary Table 9).

\section{ARB medication}

Crude and adjusted HR estimates associated with ARB prescriptions are shown in Supplementary Table 10. After adjustment, ARB users had a significantly lower risk of ICU admission (HR: $0.21,95 \%$ CI: 0.06-0.73). We further performed a stratified analysis by estimating HRs of critical events associated with average BP and BPV among patients with and without ARB prescriptions. Similar HR estimates of average SBP were found between the patients with and without ARB prescriptions for all critical events except heart failure ( $z$-test $p=0.01$ ) (Fig. 3). A significantly higher risk of heart failure was associated with SBP in the subgroup without ARB (HR $=1.73,95 \% \mathrm{CI}: 1.19-2.51)$ than in the ARB group (HR $=0.53,95 \%$ CI: $0.23-1.24)$. For the SD of SBP/DBP, significant HRs were found for all critical events in the subgroup without ARB prescriptions. Similar estimates were found in those with ARB prescriptions, though none of the estimates were statistically significant. The protective effects of mean DBP were found for all outcomes.

\section{Discussion}

Hypertension was the most common comorbidity found in hospitalized patients with COVID-19 infection. Previous studies have reported a higher risk of all-cause mortality in COVID-19 patients with concomitant hypertension [2, 23]. Our findings suggest that high SBP and PP and unstable SBP/DBP control were independently associated with greater risks of adverse outcomes, including mortality, ICU admission, and heart failure, in COVID-19 patients. To the best of our knowledge, this study is the first to comprehensively evaluate the impact of BP control and stability on the prognosis of hypertensive patients with COVID-19 infection. The findings provide important evidence for the clinical management of COVID-19 patients with hypertension.

The safety and efficacy of ARB and ACEI drugs as antihypertensive drugs in COVID-19 patients have caused debates in the literature. Some researchers raised a hypothesis that ARB and ACEI drugs could elevate ACE2 in these patients, which could potentially increase entry points for SARS-CoV-2 virus [24]. Others argued that there was no evidence to suggest that these drugs increased ACE2 levels in lung epithelial cells [25]. It also remains controversial whether ACE2 plays a protective or detrimental role in lung injury associated with COVID-19 infection $[26,27]$. Concerns have also been raised that discontinuation of routine antihypertensive treatment could increase the risk of cardiovascular events and mortality in COVID-19 patients with concomitant hypertension [28]. A recent study 
Table 2 Laboratory profile on admission, clinical courses, and outcomes of COVID-19 patients with good BP control and poor BP control during hospitalization

All Good BP control Poor BP control $p$

$(n=803) \quad(n=662) \quad(n=141)$

Laboratory findings

White blood cell count, $\times 10^{9}$ per $\mathrm{L}$

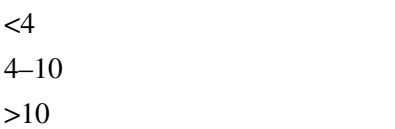

Hemoglobin, g/L

Platelet count $<100 \times 10^{9}$ per $\mathrm{L}$

Neutrophil count, mean (SD), $\times 10^{9}$ per $\mathrm{L}$

Lymphocyte count, $\times 10^{9}$ per $\mathrm{L}$

C-creative protein $>10 \mathrm{mg} / \mathrm{L}$,

Alanine aminotransferase $>40 \mathrm{U} / \mathrm{L}$

Aspartate aminotransferase $>40 \mathrm{U} / \mathrm{L}$

Albumin, g/L

Total bilirubin, $\mathrm{mmol} / \mathrm{L}$

Procalcitonin, $\mathrm{ng} / \mathrm{mL}$

Creatinine $>133 \mu \mathrm{mol} / \mathrm{L}$

Potassium, $\mathrm{mmol} / \mathrm{L}$

Sodium, mmol/L

Creatine kinase $>185$ U/L

Lactate dehydrogenase $>245$ U/L

Prothrombin time $>16 \mathrm{~s}$

Activated partial thromboplastin time, $\mathrm{s}$

D-dimer, $\mathrm{mg} / \mathrm{L}$

$$
\begin{aligned}
& \leq 0.5 \\
& 0.5-1.0 \\
& >1.0
\end{aligned}
$$

Treatment

Chinese medicine

Antibiotics

Antivirals

Corticosteroids

Intravenous immunoglobulin

Oxygen therapy

Antihypertensive drugs

Beta-blocker

Calcium antagonists

\section{ARB}

Thiazide diuretics

2 types combined

3 types combined

Outcomes

\begin{tabular}{|c|c|c|c|}
\hline $79(9.8 \%)$ & $71(10.7 \%)$ & $8(5.7 \%)$ & \\
\hline $662(82.4 \%)$ & $542(81.9 \%)$ & $120(85.1 \%)$ & \\
\hline $62(7.7 \%)$ & $49(7.4 \%)$ & $13(9.2 \%)$ & \\
\hline $121(18.1)$ & $121(17.8)$ & $122(19.5)$ & 0.775 \\
\hline $39(4.9 \%)$ & $32(4.8 \%)$ & $7(5.0 \%)$ & 1.000 \\
\hline $4.4(2.5)$ & $4.4(2.6)$ & $4.4(2.2)$ & 0.971 \\
\hline $1.5(1.0)$ & $1.5(1.1)$ & $1.5(0.6)$ & 0.924 \\
\hline $254(32.2 \%)$ & $214(32.9 \%)$ & $40(28.8 \%)$ & 0.402 \\
\hline $161(20.2 \%)$ & $143(21.8 \%)$ & $18(12.9 \%)$ & 0.023 \\
\hline $63(8.2 \%)$ & $56(8.8 \%)$ & $7(5.3 \%)$ & 0.245 \\
\hline $36.9(4.7)$ & $36.7(4.6)$ & $37.6(5.1)$ & 0.042 \\
\hline $10.9(6.7)$ & $11.1(7.1)$ & $9.6(4.3)$ & 0.001 \\
\hline $0.2(1.0)$ & $0.2(1.1)$ & $0.1(0.2)$ & 0.245 \\
\hline $35(4.4 \%)$ & $21(3.2 \%)$ & $14(10.1 \%)$ & 0.001 \\
\hline $4.2(0.6)$ & $4.2(0.6)$ & $4.2(0.5)$ & 0.173 \\
\hline $141(3.42)$ & $141(3.49)$ & $141(3.04)$ & 0.727 \\
\hline $37(4.7 \%)$ & $32(5.0 \%)$ & $5(3.7 \%)$ & 0.666 \\
\hline $183(23.4 \%)$ & $155(24.0 \%)$ & $28(20.3 \%)$ & 0.406 \\
\hline $25(3.5 \%)$ & $22(3.7 \%)$ & $3(2.4 \%)$ & 0.599 \\
\hline \multirow[t]{2}{*}{$28.3(3.9)$} & $28.3(4.0)$ & $28.0(3.4)$ & 0.350 \\
\hline & & & 0.250 \\
\hline $344(48.0 \%)$ & $275(46.6 \%)$ & $69(54.3 \%)$ & \\
\hline $174(24.3 \%)$ & $145(24.6 \%)$ & $29(22.8 \%)$ & \\
\hline $199(27.8 \%)$ & $170(28.8 \%)$ & $29(22.8 \%)$ & \\
\hline $582(72.5 \%)$ & $487(73.6 \%)$ & $95(67.4 \%)$ & 0.164 \\
\hline $304(37.9 \%)$ & $259(39.1 \%)$ & $45(31.9 \%)$ & 0.132 \\
\hline $420(52.3 \%)$ & $352(53.2 \%)$ & $68(48.2 \%)$ & 0.330 \\
\hline $118(14.7 \%)$ & $104(15.7 \%)$ & $14(9.93 \%)$ & 0.103 \\
\hline $223(27.8 \%)$ & $186(28.1 \%)$ & $37(26.2 \%)$ & 0.731 \\
\hline $603(75.1 \%)$ & $498(75.2 \%)$ & $105(74.5 \%)$ & 0.935 \\
\hline $199(24.8 \%)$ & $160(24.2 \%)$ & $39(27.7 \%)$ & 0.445 \\
\hline $581(72.4 \%)$ & $457(69.0 \%)$ & $124(87.9 \%)$ & $<0.001$ \\
\hline $100(12.5 \%)$ & $68(10.3 \%)$ & $32(22.7 \%)$ & $<0.001$ \\
\hline $33(4.1 \%)$ & $24(3.6 \%)$ & $9(6.4 \%)$ & 0.206 \\
\hline $176(21.9 \%)$ & $141(21.3 \%)$ & $35(24.8 \%)$ & 0.420 \\
\hline $40(5.0 \%)$ & $23(3.5 \%)$ & $17(12.1 \%)$ & $<0.001$ \\
\hline $35(4.8 \%)$ & $31(5.2 \%)$ & $4(3.2 \%)$ & 0.471 \\
\hline $67(8.3 \%)$ & $58(8.8 \%)$ & $9(6.4 \%)$ & 0.448 \\
\hline $30(3.7 \%)$ & $28(4.2 \%)$ & $2(1.4 \%)$ & 0.176 \\
\hline $26(3.2 \%)$ & $18(2.7 \%)$ & $8(5.7 \%)$ & 0.109 \\
\hline
\end{tabular}

$\begin{array}{lll}\text { Mortality } & 35(4.8 \%) & 31(5.2 \%) \\ \text { ICU admission } & 67(8.3 \%) & 58(8.8 \%) \\ \text { Respiratory failure } & 30(3.7 \%) & 28(4.2 \%) \\ \text { Heart failure } & 26(3.2 \%) & 18(2.7 \%)\end{array}$

$I C U$ intensive care unit, $A R B$ angiotensin II receptor blockers
0.164

0.132

0.103

0.731

0.445

$<0.001$

0.206

.420

0.001

.471

448

176 109 
Table 3 Crude and adjusted hazard ratio (HR) for critical events of COVID-19 infection associated with the average and SD of SBP/DBP, MAP, and PP in models. All the BP variables were continuous variables

\begin{tabular}{|c|c|c|c|c|c|c|c|c|}
\hline & \multicolumn{2}{|l|}{ Mortality } & \multicolumn{2}{|c|}{ ICU admission } & \multicolumn{2}{|c|}{ Respiratory failure } & \multicolumn{2}{|l|}{ Heart failure } \\
\hline & $\begin{array}{l}\text { Crude HR } \\
(95 \% \mathrm{CI})\end{array}$ & $\begin{array}{l}\text { Adjusted HR } \\
(95 \% \mathrm{CI})\end{array}$ & $\begin{array}{l}\text { Crude HR } \\
(95 \% \mathrm{CI})\end{array}$ & $\begin{array}{l}\text { Adjusted HR } \\
(95 \% \mathrm{CI})\end{array}$ & $\begin{array}{l}\text { Crude HR } \\
(95 \% \mathrm{CI})\end{array}$ & $\begin{array}{l}\text { Adjusted HR } \\
(95 \% \mathrm{CI})\end{array}$ & $\begin{array}{l}\text { Crude HR } \\
(95 \% \mathrm{CI})\end{array}$ & $\begin{array}{l}\text { Adjusted HR } \\
(95 \% \mathrm{CI})\end{array}$ \\
\hline $\begin{array}{l}\text { Average SBP } \\
\text { (per } 10 \mathrm{mmHg} \text { ) }\end{array}$ & $\begin{array}{l}0.92 \\
(0.65,1.29)\end{array}$ & $\begin{array}{l}0.94 \\
(0.59,1.52)\end{array}$ & $\begin{array}{l}0.91 \\
(0.71,1.16)\end{array}$ & $\begin{array}{l}0.99 \\
(0.69,1.41)\end{array}$ & $\begin{array}{l}0.84 \\
(0.59,1.21)\end{array}$ & $\begin{array}{l}0.77 \\
(0.42,1.39)\end{array}$ & $\begin{array}{l}1.44 * \\
(1.01,2.05)\end{array}$ & $\begin{array}{l}1.89 * \\
(1.15,3.13)\end{array}$ \\
\hline $\begin{array}{l}\text { Average DBP } \\
\text { (per } 10 \mathrm{mmHg} \text { ) }\end{array}$ & $\begin{array}{l}0.32 * * * \\
(0.21,0.49)\end{array}$ & $\begin{array}{l}0.95 \\
(0.48,1.88)\end{array}$ & $\begin{array}{l}0.31 * * * \\
(0.23,0.42)\end{array}$ & $\begin{array}{l}0.65 \\
(0.40,1.07)\end{array}$ & $\begin{array}{l}0.27 * * * \\
(0.17,0.43)\end{array}$ & $\begin{array}{l}1.03 \\
(0.49,2.17)\end{array}$ & $\begin{array}{l}0.61 \\
(0.34,1.07)\end{array}$ & $\begin{array}{l}1.38 \\
(0.65,2.90)\end{array}$ \\
\hline $\begin{array}{l}\text { SBP variability } \\
\text { (per } 1 \mathrm{mmHg} \text { ) }\end{array}$ & $\begin{array}{l}1.17 * * * \\
(1.13,1.23)\end{array}$ & $\begin{array}{l}1.23 * * * \\
(1.11,1.36)\end{array}$ & $\begin{array}{l}1.10 * * * \\
(1.06,1.15)\end{array}$ & $\begin{array}{l}1.12 * * * \\
(1.05,1.20)\end{array}$ & $\begin{array}{l}1.09 * * \\
(1.03,1.15)\end{array}$ & $\begin{array}{l}1.07 \\
(0.95,1.19)\end{array}$ & $\begin{array}{l}1.11 * * * \\
(1.05,1.18)\end{array}$ & $\begin{array}{l}1.09 \\
(0.99,1.20)\end{array}$ \\
\hline $\begin{array}{l}\text { DBP variability } \\
\text { (per } 1 \mathrm{mmHg} \text { ) }\end{array}$ & $\begin{array}{l}1.27 * * * \\
(1.19,1.37)\end{array}$ & $\begin{array}{l}1.33 * * * \\
(1.12,1.57)\end{array}$ & $\begin{array}{l}1.17 * * * \\
(1.10,1.25)\end{array}$ & $\begin{array}{l}1.20 * * * \\
(1.08,1.33)\end{array}$ & $\begin{array}{l}1.13 * \\
(1.02,1.26)\end{array}$ & $\begin{array}{l}1.08 \\
(0.85,1.38)\end{array}$ & $\begin{array}{l}1.15^{* *} \\
(1.04,1.28)\end{array}$ & $\begin{array}{l}1.06 \\
(0.90,1.24)\end{array}$ \\
\hline $\begin{array}{l}\text { MAP } \\
(\text { per } 10 \mathrm{mmHg})\end{array}$ & $\begin{array}{l}0.42 * * * \\
(0.26,0.68)\end{array}$ & $\begin{array}{l}0.94 \\
(0.50,1.77)\end{array}$ & $\begin{array}{l}0.42 * * * \\
(0.29,0.59)\end{array}$ & $\begin{array}{l}0.76 \\
(0.47,1.23)\end{array}$ & $\begin{array}{l}0.36^{* * * *} \\
(0.22,0.60)\end{array}$ & $\begin{array}{l}0.89 \\
(0.43,1.83)\end{array}$ & $\begin{array}{l}0.97 \\
(0.56,1.70)\end{array}$ & $\begin{array}{l}1.79 \\
(0.90,3.54)\end{array}$ \\
\hline $\begin{array}{l}\text { PP } \\
\text { (per } 10 \mathrm{mmHg} \text { ) }\end{array}$ & $\begin{array}{l}1.72 * * \\
(1.23,2.41)\end{array}$ & $\begin{array}{l}0.93 \\
(0.45,1.90)\end{array}$ & $\begin{array}{l}1.81 * * * \\
(1.41,2.32)\end{array}$ & $\begin{array}{l}1.40 \\
(0.87,2.24)\end{array}$ & $\begin{array}{l}1.69 * * * \\
(1.20,2.40)\end{array}$ & $\begin{array}{l}0.50 \\
(0.19,1.29)\end{array}$ & $\begin{array}{l}2.02 * * * \\
(1.39,2.92)\end{array}$ & $\begin{array}{l}2.71 * * \\
(1.39,5.29)\end{array}$ \\
\hline
\end{tabular}

Full models adjusted for SBP and DBP on admission, age, sex, disease severity status, smoking, drinking, and coexisting comorbidities (cancer, diabetes, coronary heart disease, cerebrovascular disease, COPD, chronic liver disease, and chronic kidney disease). All the BP variables were continuous variables

$S B P$ systolic blood pressure, $D B P$ diastolic blood pressure, $M A P$ mean arterial pressure, $P P$ pulse pressure, $S D$ standard deviation, $H R$ hazard ratio, $C I$ confidence interval, ICU intensive care unit

$* p<0.05 ; * * p<0.01 ; * * * p<0.00$

a)

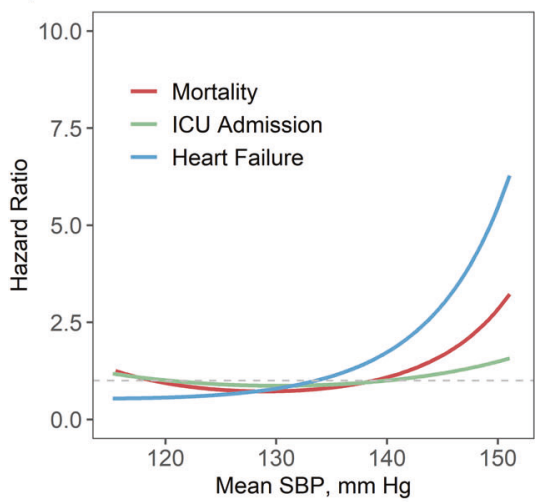

d)

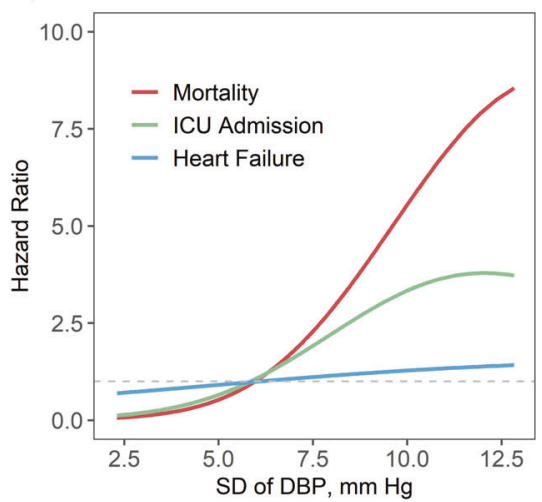

b)

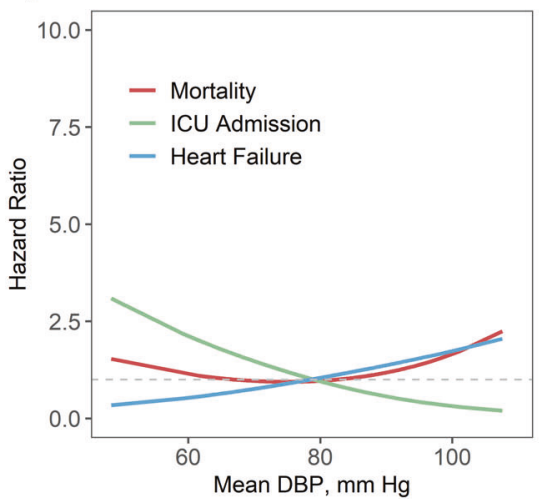

e)

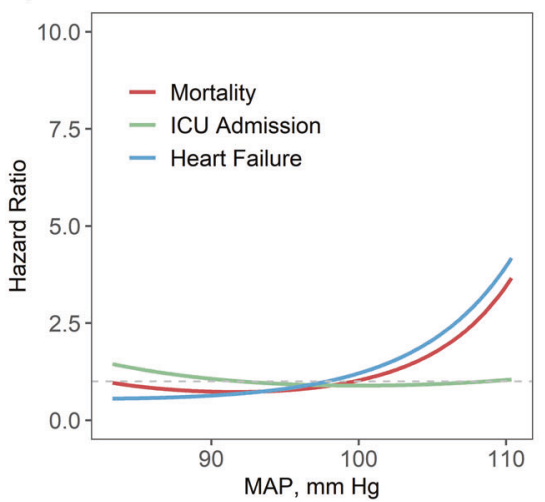

c)

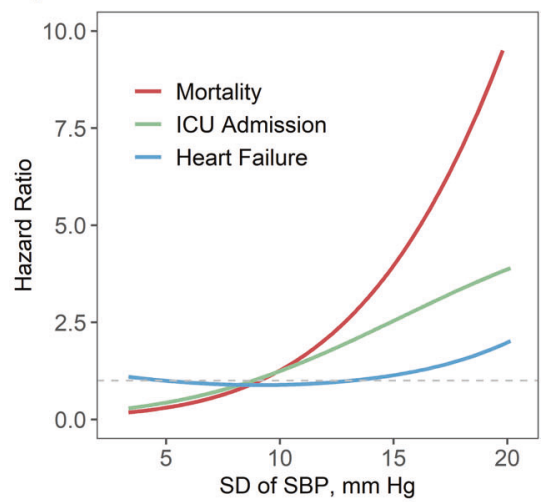

f)

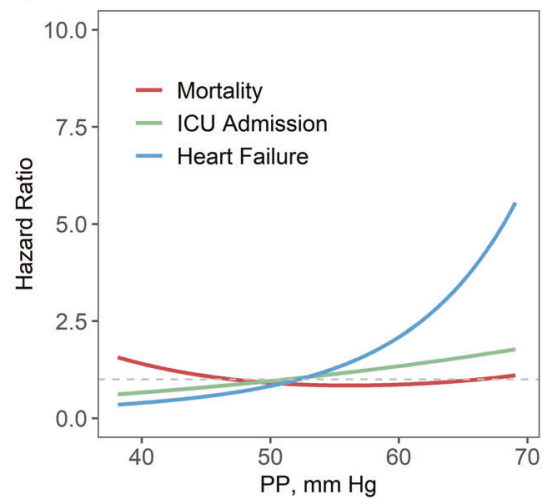

Fig. 2 Dose-response relationships of mortality, ICU admission, and heart failure associated with the mean and standard deviation (SD) of a-d SBP/DBP, e MAP, and f PP in 803 COVID-19 patients with coexisting hypertension 
a) Mean SBP per $10 \mathrm{~mm} \mathrm{Hg}$

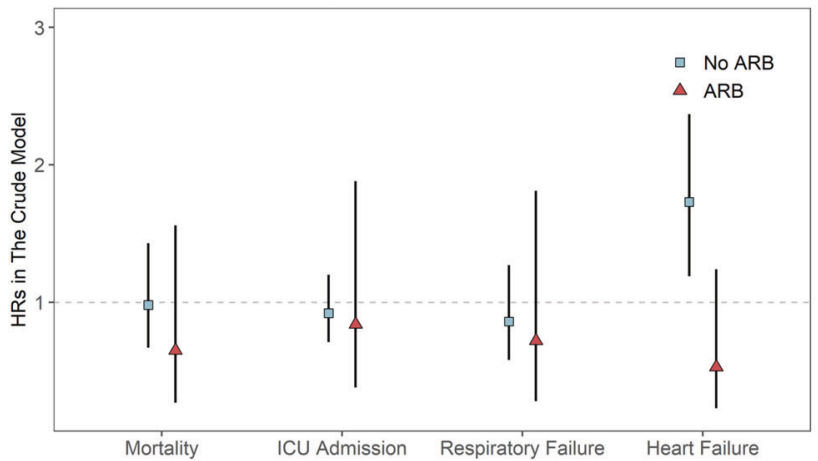

c) Mean DBP per $10 \mathrm{~mm} \mathrm{Hg}$

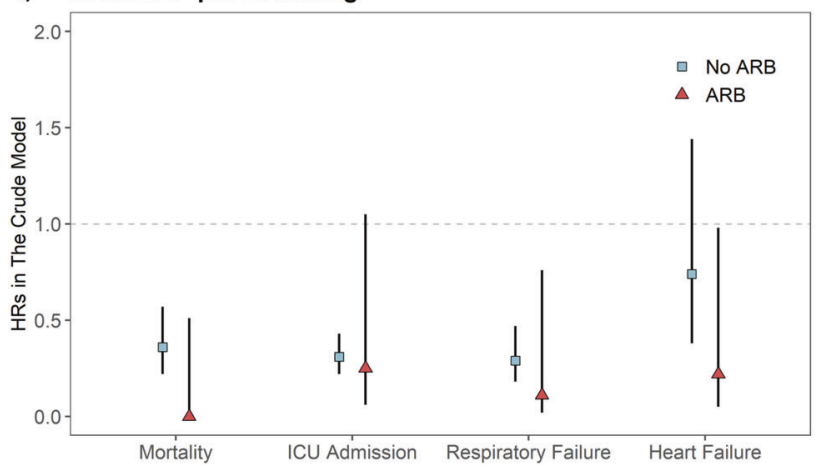

b) SD of SBP per $1 \mathrm{~mm} \mathrm{Hg}$

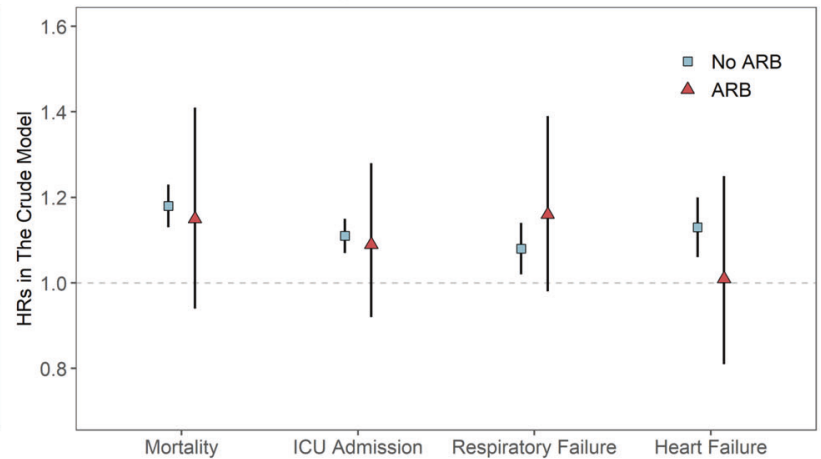

d) SD of DBP per $1 \mathrm{~mm} \mathrm{Hg}$

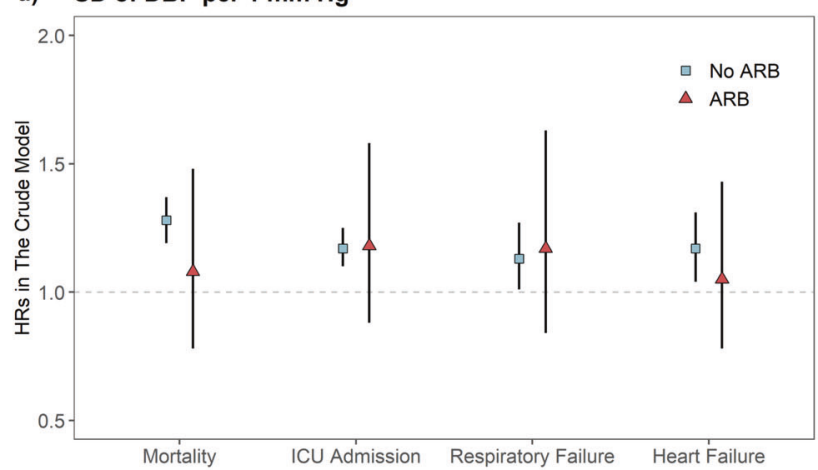

Fig. 3 Crude hazard ratio (HR) for critical events associated with mean and standard deviation (SD) of a, b SBP and c, d DBP in COVID-19 patients with ARB prescriptions (red triangle) and those with prescriptions for other antihypertensive medication or without any (blue square). Vertical bars indicate $95 \%$ confidence intervals

in the USA found that ARB/ACEI use did not increase COVID-19 infection risk [29]. In our study, we found that ARB users had a lower risk of ICU admission but did not significantly differ from non-ARB users in other outcomes. We compared the risk estimates associated with different $\mathrm{BP}$ variables between the two ARB groups. There was no significant difference in these estimates, except a relatively smaller HR of heart failure associated with SBP in the ARB group. Our findings echo the findings of the study by Zhang et al. that the in-hospital use of ARBs/ACEIs was associated with a lower mortality risk in hypertensive patients with COVID-19 [23]. Our analysis further revealed that the adverse effects of poor BP control did not significantly differ between the patients, regardless of receiving ARBs during hospitalization. Therefore, our findings support the current statements from both the European Society of Cardiology and the American Heart Association, which suggested that patients with hypertension should continue ARB and ACEI treatment if they already had these drugs in their usual regimens [30, 31]. Unfortunately, none of the patients used ACEIs as an antihypertensive drug in our study; therefore, we were unable to assess the effect of this type of drug. Future studies from other countries are warranted to investigate the adverse or beneficial effects of ARBs and ACEIs given potential ethnic differences.
The mortality rate of our patients $(66 / 803,8.2 \%)$ was comparable to that reported for inpatients with coexisting hypertension in other hospitals in China (8.8\%) [23]. Consistent with the previous findings on cardiovascular risks of hypertension [32], we found that the risks of adverse outcomes of heart failure significantly increased in patients with high SBP, but such a trend was less evident for DBP. This finding indicates that high BP is a significant predictor of unfavorable prognosis of COVID19 and that SBP is the primary target of BP control in COVID-19 patients. However, high SBP/DBP variability was associated with high risks of mortality and ICU admissions, suggesting the importance of maintaining stable in-hospital BP in these patients. High BPV might reflect arterial stiffness and endothelial dysfunction, which increase the risk of cardiovascular events [33-35]. Another possibility was a sudden BP decrease due to rapid deterioration of underlying conditions. We performed a sensitivity analysis by excluding the patients with at least one record of hypotension (both SBP/DBP $<90 / 60$ $\mathrm{mmHg}$ ). The estimates of BPV were consistent with the main results (Supplementary Table 9). The underlying mechanism of the association between high BPV and severe outcomes in COVID-19 patients warrants further investigation. 
Our study has a few caveats. First, the data were from one hospital in Wuhan and might not be generalized to all COVID patients in China and other countries. Second, due to the overwhelmed healthcare system in Wuhan, most patients in our study were admitted 2-3 weeks after symptom onset. Therefore, the impact of BPV on the early progression of COVID-19 cannot be assessed. Third, there were no data on baseline BP or antihypertensive drugs taken before hospital admission; hence, data on the long-term intake of ACEIs or ARBs were not available in these patients, which could have some residual effects on cardiovascular events in this retrospective cohort. Fourth, BP monitoring probably has been enhanced in those with high BP and complicated by disease progression, which could have resulted in biased effect estimates. Nevertheless, in the sensitivity analysis, we also used the CV of SBP as an exposure in our model, which was believed to partially address this bias. This sensitivity analysis yielded similar but slightly more conservative estimates, suggesting that SBP/DBP variability had significant adverse effects on clinical outcomes of COVID-19 infection, independent of average BP. Last but not least, the disease outcomes of ICU admission, respiratory failure, and heart failure might not be objective. Nevertheless, the diagnostic criteria were strictly followed, and clinical decisions involved at least one senior and one junior doctor.

\section{Conclusion}

In this retrospective study of 803 COVID-19 patients with coexisting hypertension, we found that high average SBP and high SBP/DBP variability during hospitalization were independently associated with in-hospital mortality, ICU admission, and heart failure. The findings suggest that low and stable BP are optimal to achieve a favorable prognosis for COVID-19 patients with coexisting hypertension. Another finding with clinical implications is that ARB drugs did not cause higher risks of adverse outcomes in hypertensive patients, and even a benefit in regard to heart failure was observed. This supports the continuation of ARB drugs in COVID-19 patients.

Acknowledgements The authors would like to thank Dr. Hua Luo for helpful discussion on this paper.

Funding LY and DH are supported by the Alibaba (China)—Hong Kong Polytechnic University Collaborative Research Fund (P0031768). PC is supported by the National Natural Science Foundation of China (No. 81903406).

Author contributions LY is the guarantor of the paper, including its content, data, and analysis. JR, YS, ZZ, SZ, LH and LY originated and designed the study. YS and YG contributed to data collection. JR, ZZ, SZ, LH, and PC contributed to data cleaning. JR, ZZ, SZ, and LH conducted the data analysis. JR, LX, and LY interpreted the findings and drafted the paper. JR, SZ, LH, LX, DH, FW, JQ, and LY reviewed and edited the paper. All the authors approved the final version of this paper.

\section{Compliance with ethical standards}

Conflict of interest The authors declare that they have no conflict of interest.

Ethical approval Ethical approval was obtained from the No. 923 Hospital of Joint Service Supporting Force in China, which led the military medical team in Huoshenshan Hospital and officially kept the database of electronic medical records with all personal information removed after the hospital was closed on April 15, 2020.

Publisher's note Springer Nature remains neutral with regard to jurisdictional claims in published maps and institutional affiliations.

\section{References}

1. Huang C, Wang Y, Li X, Ren L, Zhao J, Hu Y, et al. Clinical features of patients infected with 2019 novel coronavirus in Wuhan, China. Lancet. 2020;395:497-506.

2. Zhou F, Yu T, Du R, Fan G, Liu Y, Liu Z, et al. Clinical course and risk factors for mortality of adult inpatients with COVID-19 in Wuhan, China: a retrospective cohort study. Lancet. 2020;395:1054-62.

3. Guan WJ, Liang WH, Zhao Y, Liang HR, Chen ZS, Li YM, et al. Comorbidity and its impact on 1590 patients with COVID-19 in China: a nationwide analysis. Eur Respir J. 2020;55:2000547.

4. Guan WJ, Ni ZY, Hu Y, Liang WH, Ou CQ, He JX, et al. Clinical characteristics of coronavirus disease 2019 in China. N Engl J Med. 2020;382:1708-20.

5. Wang D, Hu B, Hu C, Zhu F, Liu X, Zhang J, et al. Clinical characteristics of 138 hospitalized patients with 2019 novel coronavirus-infected pneumonia in Wuhan, China. JAMA. 2020;323:1061-9.

6. Wu C, Chen X, Cai Y, Zhou X, Xu S, Huang H, et al. Risk factors associated with acute respiratory distress syndrome and death in patients with coronavirus disease 2019 pneumonia in Wuhan, China. JAMA. 2020;180:1-11.

7. Grasselli G, Zangrillo A, Zanella A, Antonelli M, Cabrini L, Castelli A, et al. Baseline characteristics and outcomes of 1591 patients infected with SARS-CoV-2 admitted to ICUs of the Lombardy Region, Italy. JAMA. 2020;323:1574-81.

8. Richardson S, Hirsch JS, Narasimhan M, Crawford JM, McGinn T, Davidson KW, et al. Presenting characteristics, comorbidities, and outcomes among 5700 patients hospitalized with COVID-19 in the New York City Area. JAMA. 2020;323:2052-9.

9. Clark CE, McDonagh STJ, McManus R, Martin U. Covid-19 and hypertension: risks and management. https://blogs.bmj.com/bmj/ 2020/04/15/covid-19-and-hypertension-risks-and-management/. Accessed 17 April 2020.

10. Nicin L, Abplanalp WT, Mellentin H, Kattih B, Tombor L, John $\mathrm{D}$, et al. Cell type-specific expression of the putative SARS-CoV2 receptor ACE2 in human hearts. Eur Heart J. 2020;41:1804-6.

11. Zhou P, Yang XL, Wang XG, Hu B, Zhang L, Zhang W, et al. A pneumonia outbreak associated with a new coronavirus of probable bat origin. Nature. 2020;579:270-3.

12. Hamming I, Timens W, Bulthuis ML, Lely AT, Navis G, van Goor H. Tissue distribution of ACE2 protein, the functional receptor for SARS coronavirus. A first step in understanding SARS pathogenesis. J Pathol. 2004;203:631-7. 
13. Sanders JM, Monogue ML, Jodlowski TZ, Cutrell JB. Pharmacologic treatments for coronavirus disease 2019 (COVID-19): a review. JAMA. 2020. https://doi.org/10.1001/jama.2020.6019.

14. Fang L, Karakiulakis G, Roth M. Are patients with hypertension and diabetes mellitus at increased risk for COVID-19 infection? Lancet Respir Med. 2020;8:e21.

15. Kuba K, Imai Y, Rao S, Gao H, Guo F, Guan B, et al. A crucial role of angiotensin converting enzyme 2 (ACE2) in SARS coronavirus-induced lung injury. Nat Med. 2005;11:875-9.

16. Parati G, Ochoa JE, Lombardi C, Bilo G. Assessment and management of blood-pressure variability. Nat Rev Cardiol. 2013;10:143-55.

17. Yang $M$, Pan X, Liang Z, Huang X, Duan M, Cai H, et al. Association between blood pressure variability and the short-term outcome in patients with acute spontaneous subarachnoid hemorrhage. Hypertens Res. 2019;42:1701-7.

18. Guo Z-D, Wang Z-Y, Zhang S-F, Li X, Li L, Li C, et al. Aerosol and surface distribution of severe acute respiratory syndrome coronavirus 2 in hospital wards, Wuhan, China, 2020. Emerg Infect Dis. 2020;26:1583-91.

19. National Health Commission of China. New coronavirus pneumonia prevention and control program. http://www.nhc.gov.cn/ yzygj/s7652m/202002/41c3142b38b84ec4a748e60773cf9d4f. shtml. Accessed 22 Mar 2020.

20. Williams B, Mancia G, Spiering W, Agabiti Rosei E, Azizi M, Burnier M, et al. 2018 ESC/ESH Guidelines for the management of arterial hypertension. Eur Heart J. 2018;39:3021-104.

21. Unger T, Borghi C, Charchar F, Khan NA, Poulter NR, Prabhakaran D, et al. 2020 International Society of Hypertension Global Hypertension Practice Guidelines. Hypertension. 2020;75: 1334-57.

22. Ponikowski P, Voors AA, Anker SD, Bueno H, Cleland JGF, Coats AJS, et al. 2016 ESC Guidelines for the diagnosis and treatment of acute and chronic heart failure: the Task Force for the Diagnosis and Treatment of Acute and Chronic Heart Failure of the European Society of Cardiology (ESC) Developed with the special contribution of the Heart Failure Association (HFA) of the ESC. Eur Heart J. 2016;37:2129-200.

23. Zhang P, Zhu L, Cai J, Lei F, Qin JJ, Xie J, et al. Association of inpatient use of angiotensin-converting enzyme inhibitors and angiotensin ii receptor blockers with mortality among patients with hypertension hospitalized with COVID-19. Circ Res. 2020;126:1671-81.

24. Guo J, Huang Z, Lin L, Lv J. Coronavirus disease 2019 (COVID19) and cardiovascular disease: a viewpoint on the potential influence of angiotensin-converting enzyme inhibitors/angiotensin receptor blockers on onset and severity of severe acute respiratory syndrome coronavirus 2 infection. J Am Heart Assoc. 2020;9: e016219.

25. Vaduganathan M, Vardeny O, Michel T, McMurray JJ, Pfeffer MA, Solomon SD. Renin-angiotensin-aldosterone system inhibitors in patients with Covid-19. N Engl J Med. 2020;382:1653-9.

26. Kuster GM, Pfister O, Burkard T, Zhou Q, Twerenbold R, Haaf P, et al. SARS-CoV2: should inhibitors of the renin-angiotensin system be withdrawn in patients with COVID-19? Eur Heart J. 2020;41:1801-3.

27. Sommerstein R, Kochen MM, Messerli FH, Grani C. Coronavirus disease 2019 (COVID-19): do angiotensin-converting enzyme inhibitors/angiotensin receptor blockers have a biphasic effect? J Am Heart Assoc. 2020;9:e016509.

28. Esler M, Esler D. Can angiotensin receptor-blocking drugs perhaps be harmful in the COVID-19 pandemic? J Hypertens. 2020;38:781-2.

29. Mehta N, Kalra A, Nowacki AS, Anjewierden S, Han Z, Bhat P, et al. Association of use of angiotensin-converting enzyme inhibitors and angiotensin ii receptor blockers with testing positive for coronavirus disease 2019 (COVID-19). JAMA Cardiol. 2020. https://doi.org/10.1001/jamacardio.2020.1855.

30. European Society for Cardiology. Position statement of the ESC Council on Hypertension on Ace-inhibitors and Angiotensin Receptor Blockers. https://www.escardio.org/Councils/Council-onHypertension-(CHT)/News/position-statement-of-the-esc-councilon-hypertension-on-ace-inhibitors-and-ang. Accessed 7 April 2020.

31. American Heart Association. Patients taking ACE-i and ARBs who contract COVID-19 should continue treatment, unless otherwise advised by their physician. https://newsroom.heart.org/ news/patients-taking-ace-i-and-arbs-who-contract-covid-19should-continue-treatment-unless-otherwise-advised-by-theirphysician. Accessed 7 April 2020.

32. Benetos A, Thomas F, Bean K, Gautier S, Smulyan H, Guize L. Prognostic value of systolic and diastolic blood pressure in treated hypertensive men. Arch Intern Med. 2002;162:577-81.

33. Nagai M, Hoshide S, Ishikawa J, Shimada K, Kario K. Visit-tovisit blood pressure variations: new independent determinants for carotid artery measures in the elderly at high risk of cardiovascular disease. J Am Soc Hypertens. 2011;5:184-92.

34. Diaz KM, Veerabhadrappa P, Kashem MA, Feairheller DL, Sturgeon KM, Williamson ST, et al. Relationship of visit-to-visit and ambulatory blood pressure variability to vascular function in African Americans. Hypertens Res. 2012;35:55-61.

35. Chang TI, Reboussin DM, Chertow GM, Cheung AK, Cushman WC, Kostis WJ, et al. Visit-to-visit office blood pressure variability and cardiovascular outcomes in SPRINT (Systolic Blood Pressure Intervention Trial). Hypertension. 2017;70:751-8. 